\title{
Prevalence and associated factors of common mental disorders among adult patients attending HIV follow up service in Harar town, Eastern Ethiopia: a cross- sectional study
}

\author{
Aboma Motumma', Lemma Negesa ${ }^{1}$, Gari Hunduma² and Tilahun Abdeta ${ }^{2,3 *}$
}

\begin{abstract}
Background: In developed countries, there are well documented mental health impacts of HIV/AIDS and patients' quality of life. Acquiring HIV/AIDS can be a serious psychological trauma and can predispose a person to different mental disorders. Co-occurring mental illness complicates diagnosis, help-seeking, quality of care provided, treatment outcomes and adherence. However, in Ethiopia, studies about mental health problems in HIV/AIDS treatment settings are limited. The purpose of the current study is to determine the prevalence and associated factors of common mental disorders among adult HIV/AIDS patients undergoing HIV service in Harar town, eastern Ethiopia. Conducting this study is important as baseline information for the concerned stakeholders including health professionals and policymakers and in general to improve the quality of care for HIV/AID patients.

Methods: Institution based cross-sectional study was conducted. We collected data from 420 adult patients through a face to face interviewing technique using a standardized questionnaire and review of medical records. Bivariable and multivariable (binary logistic regression) analyses were used to check the association between common mental disorders (CMDs) and independent variables. Variables which have a $p$-value $<0.05$ during bivariable regression were entered into multivariable (binary logistic regression) and finally which have a p-value of $<0.05$ under multivariable (binary logistic regression) were identified as statistically significant association at 95\% of confidence interval.

Results: All 420 patients were interviewed providing response rate 100\%. The result revealed that (28.1\%; $95 \%$ Cl; 26.14, 30.06) of HIV/AIDS patients had CMD. In the final model, stage 4 HIV/AIDS (Adjusted Odds Ratio 3.37, 95\% Cl: $1.45,7.83$ ), family history of mental illness (AOR 2.65, 95\% Cl: 1.26, 5.54) and current drinking alcohol (AOR 5.1, 95\% $\mathrm{Cl}: 2.04,12.79)$ were found having statistically significant association with CMD.

Conclusions: This study investigated the prevalence and associated factors of CMD among adults living with HIV/ AIDS. HIV/AIDS stage, having family history of mental illness and current drinking alcohol were the main identified associated factors of CMD. These factors are important for the hospitals and other concerned bodies for providing prevention and appropriate intervention of common mental disorders among HIV/AIDS patients.
\end{abstract}

Keywords: Prevalence, Associated factors, CMDs, HIV/AIDS, Adult patients, Ethiopia

\footnotetext{
*Correspondence: tilahunabdeta@gmail.com

${ }^{2}$ Department of Psychiatry, College of health and medical sciences, School of

Nursing and Midwifery, Haramaya University, Harar, Ethiopia

${ }^{3}$ Centre for International Health, Ludwig Maxmillians University, Munich,

Germany

Full list of author information is available at the end of the article
}

(c) The Author(s). 2019 Open Access This article is distributed under the terms of the Creative Commons Attribution 4.0 International License (http://creativecommons.org/licenses/by/4.0/), which permits unrestricted use, distribution, and reproduction in any medium, provided you give appropriate credit to the original author(s) and the source, provide a link to the Creative Commons license, and indicate if changes were made. The Creative Commons Public Domain Dedication waiver (http://creativecommons.org/publicdomain/zero/1.0/) applies to the data made available in this article, unless otherwise stated. 


\section{Background}

Mental illness is among many non-AIDS complications that limit the HIV/AIDS patients' quality of life (QOL) [1, 2]. Mental illness and HIV infection are linked in many ways including (I) HIV infection often result in serious emotional disturbance due to its malignant course and associated stigma [3]. (II) HIV has direct effects on a central nervous system which may lead to cognitive, perceptual and behavioral changes [3]. (III) Mental illness can be a consequence of opportunistic neurological and systemic infections and their treatments [4]. (IV) Some Highly Active Antiretroviral Therapy (HAART) have psychiatric side effects [4]. $(V)$ Patients of severe mental illness are at risk to HIV infection [5]. (VI) HIV and psycho-active Substance use is connected in direct ways (IV use) and in indirect ways influencing sexual behavior [35]. There are many reported impacts of mental health problems among HIV/AIDS patients including speeding up the disease progression, reducing adherence to treatments, affecting willingness or ability to access health care and increased risk of transmission of other sexually transmitted infections (STI) by increasing high-risk behaviors [6].

Common mental disorders (CMDs) is set of signs and symptoms of non-psychotic depression, anxiety, and somatoform disorders and it is frequently reported among HIV infected people [7-12]. The magnitude of major depressive disorder (MDD) ranges from 16.2 to $36 \%$ among HIV patients in the USA [13]. This is as compared to the general population's prevalence $4.2 \%$, it is 4 to 7 fold greater [14]. Another study in LAMIC (Kenya, Democratic Republic of Congo and Thailand) again reported that depression is higher in HIV patients than in HIV negative individuals [15]. However, these studies on co-occurring of mental illness and HIV-infection is still limited in sub-Saharan Africa including Ethiopia [16-18]. The study on Anxiety Disorders among adult HIV/AIDS patients in a Sub-Saharan Africa revealed that the magnitude of anxiety disorders and mixed anxiety-depressive disorder among adult PLWHA was 21.7, and $5.3 \%$ respectively. Lack of family support, unemployment and being unmarried were factors significantly associated with anxiety disorders among participants [19]. Study in Nigeria showed that individuals with HIV had significantly higher rates of common mental disorder $(\mathrm{OR}=3.58,95 \% \mathrm{CI}=1.44-8.94)$ than healthy people and stage of the HIV was significantly associated with common mental disorder [7]. A systematic review and meta-analysis result in sub-Saharan Africa revealed that prevalence estimates of depression ranged between 9 and 32\% in PLWHA on Antiretroviral Therapy (ART) and in untreated or mixed (treated/untreated) ones. Low socio-economic conditions in PLWHA on ART, female sex and immunosuppression in mixed/untreated PLWHA were reported associated factors [20].

The aim of the current study is to determine the magnitude of common mental disorders and factors associated with it among HIV positive individuals undergoing HIV services in Harar town, Eastern Ethiopia. It is important as baseline information for the concerned stakeholders including health professionals and policymakers and in general to improve the quality of care for HIV/ AID patients.

\section{Methods}

\section{Study Area}

We conducted the study in Harar town, Harari regional state, Eastern Ethiopia, at Hiwot Fana specialized University and Jugel governmental Hospital. Location of Harar is $527 \mathrm{~km}$ from the capital city of Ethiopia, Addis Ababa to the direction of the east. In Harar town, there are 19 health posts, 2 private hospitals, 8 health centers, 1 FGAE (Family Guidance Association of Ethiopia) clinic, 3 government hospitals and one university specialized hospital. During our study, a total of 7558 HIV patients were enrolled at ART clinic in the town. Hiwot Fana and Jugel hospitals are the major ART sites in the region.

\section{Study design}

We conducted through facility-based Cross-sectional study design.

\section{Source population}

Adult Sero-positive individuals in Harar town, Eastern Ethiopia.

\section{Study population}

The 420 randomly selected adult HIV patients enrolled in HIV services (Pre-ART and on ART) at Hiwot Fana specialized University Hospital and Jugel governmental Hospital in Harar town, Eastern Ethiopia and who were 18 years or older were included in the study and patients who were critically ill during data collection period were excluded.

\section{Sample size determination}

We calculated Sample size using single population proportion formula taking $p=46.7 \%$ from previous study "Prevalence of common mental disorders among HIV/AIDS patients in Ethiopia" [8], d of precision 5, 95\% confidence interval and $10 \%$ non- response rate. 


$$
\begin{gathered}
\mathrm{n}=\frac{(\mathrm{z \alpha} / 2)^{2} \mathrm{p}(1-\mathrm{p})}{\mathrm{d}^{2}} \text { where } \mathrm{n}=\text { sample size, } \mathrm{Z \alpha} / 2=\mathrm{Z} \text { score at } 95 \% \mathrm{CI}=1.96, \mathrm{p}=46.7 \% \text { and } \mathrm{d}=5 \%(0.05) \\
\mathrm{n}=\frac{(1.96)^{2} 0.467(1-0.467)}{(0.05)^{2}}=\frac{3.8416 \times 0.467 \times 0.533}{0.0025}=\mathbf{3 8 2}
\end{gathered}
$$

Final sample size with $10 \%$ non-response rate was $\mathbf{4 2 0}$.

\section{Sampling technique}

During our study period, there were 7558 registered HIV/AIDS patients enrolled in HIV services at both Hiwot Fana University specialized and Jugel governmental hospitals. Final sample size (420) was proportionally allocated to each hospital 281 from Hiwot Fana and 139 from Jugel hospital. At each hospital patients were stratified into pre-ART and ART based on their ART status. Then we selected eligible patients by simple random sampling technique based on their card number (Fig. 1).

\section{Data collection}

We collected data through patient interview and review of medical records. Data regarding socio-demographics, CMDs, majority of clinical and psychosocial variables like (perceived HIV stigma, partner's Sero-status, Children's Sero status, death of either partner or family members due to HIV/AIDS, hospitalized in the last month, decreased level of functioning than usual, lost job due to HIV/AIDS, faced severe stress in the last 6 months, having family history of mental illness and having any comorbid chronic physical illness) and Substance-related variables (current drinking alcohol, chewing Khat, smoking cigarette, and using illicit substances) were retrieved by Interviewing patients using the adopted standardized questionnaire through face to face interview using interviewer-administered a standardized questionnaire. However, Respective medical Records like (HIV/AIDS stage, CD4 count and started ART) were obtained from patients' medical record. We used Self Reporting Questionnaire (SRQ-20) to get data about CMDs. We used standardized questionnaire in interview-form instead of self-report because of the $16.2 \%$ (68) of our study participants were unable to read and write and they could not fill the questionnaire. The questionnaire was translated into local languages Afan Oromo and Amharic and validated to Ethiopian context.

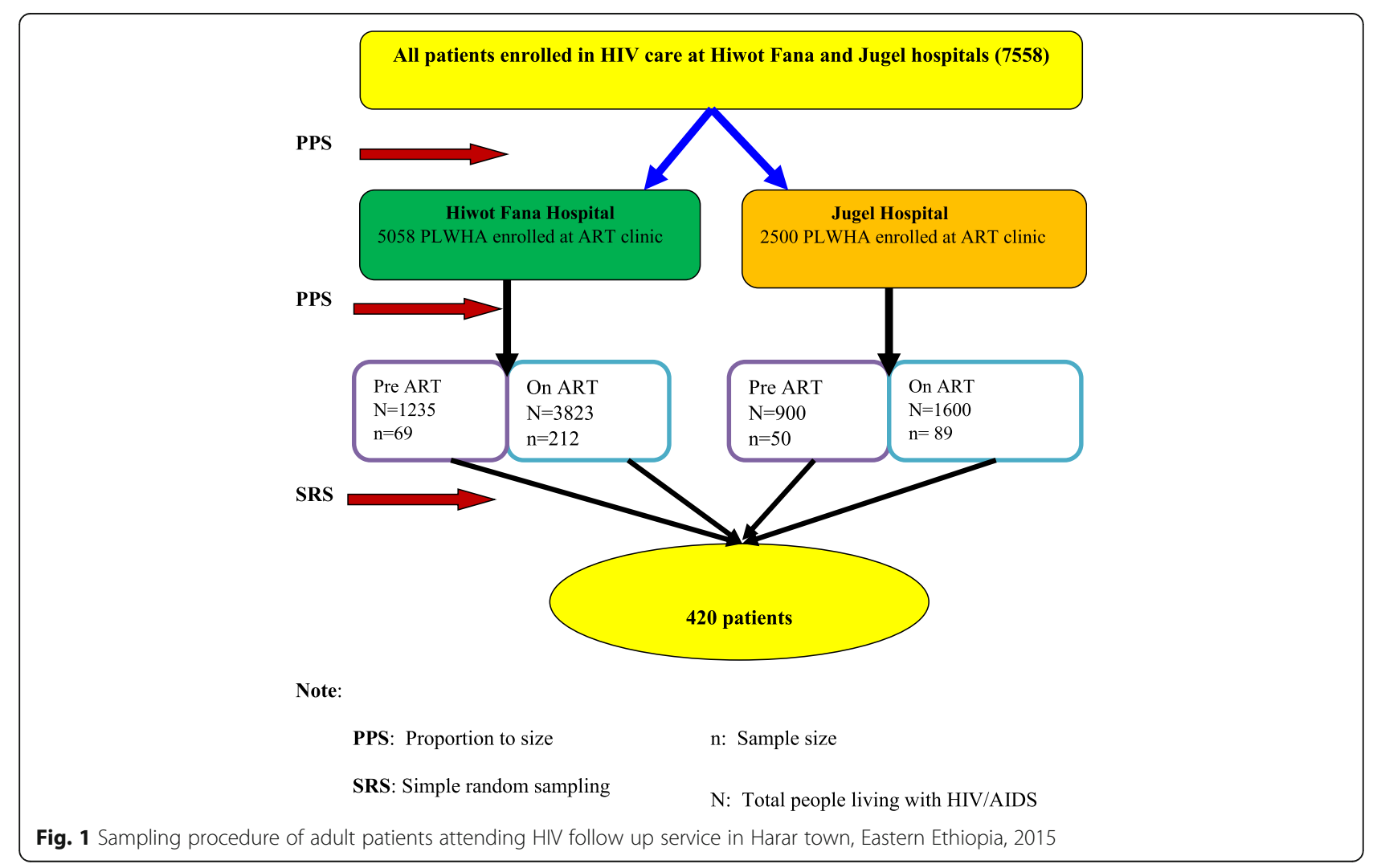


As common mental disorders (CMDs) refers to the set of signs and symptoms of non-psychotic depression, anxiety, and somatoform disorders, considering how challenging it can be to diagnose these disorders in primary care practice, the World Health Organization (WHO) developed the Self Reporting Questionnaire (SRQ-20), a screening instrument to identify suspected CMDs cases in primary care settings [21]. The SRQ-20 has 20 yes/no questions and it has been validated in Ethiopia, with high sensitivity (85.7\%) and specificity (75.6\%) [22]. Cut point of SRQ-20 is different in institution based and community based and usually cut-point of $\geq 7$ is used in institution based [22] Data collectors were 5 diploma nurses with previous data collection experience and supervisors were 3-graduate nurses and all of them were given one-days training prior to the data collection period. The study was conducted after approval obtained from the College of Health and Medical Sciences, Institutional Research Ethics Review Committee (IRERC) of Haramaya University. Written informed consent was obtained from the study participants after providing a clear explanation of the objective of the study. The collected data were kept confidential. Participants' right to refuse and the chance to ask anything about the study was respected. The names of the participants were not written.

\section{Study Variables}

\section{Dependent variable}

Status of common mental disorder (yes/no).

\section{Independent Variables}

Socio-demographic variables (age, sex, religion, ethnicity, marital status, occupational status, income, and educational status), clinical and psychosocial variables (HIV/AIDS stage, CD4 count, started ART, perceived HIV stigma, partner's Sero-status, Children's Sero status, death of either partner or family members due to HIV/ AIDS, hospitalized in the last month, decreased level of functioning than usual, lost job due to HIV/AIDS, faced severe stress in the last 6 months, having family history of mental illness and having any comorbid chronic physical illness), Substance-related variables (current drinking alcohol, chewing Khat, smoking cigarette, and using illicit substances).

\section{Data processing and analysis}

After checking for completeness data were entered into a computer using EpiData 3.1 then exported to SPSS for analysis. In statistical analysis we used categorical variables. Our dependent variable (CMD) is dichotomous which is categorized as yes (having CMD) or no (have no CMD). Since our dependent variable was dichotomous and we used cross-sectional study design, in order to explore the relationship between dependent variable and each independent variable we run a bivariate analysis using odds ratio (OR) of chi square. All independent variables that have a significant association with dependent variable (CMD) during bivariate analysis were adjusted together into multivariate analysis specifically binary logistic regression in order to control confounders. A $p$ value of $<0.05$ was considered as statistically significant association at $95 \%$ of confidence interval. We used Descriptive analysis to describe variables using frequencies, percentages, tables, and figures.

\section{Data quality control}

To control the quality of data, we used the standard questionnaire in the Ethiopian context. The pretest was done at another Hospital and necessary adjustments were done before the actual data collection time. Data collectors collected data under the close supervision of trained supervisors. A one-day training about the objective of the study and other related issues was given for data collectors and supervisors.

\section{Operational Definition}

Common mental disorders: Patients who scored $\geq 7$ of SRQ-20 items were considered as having CMD [8]. Current substance use: Is defined as participants who had used substances at least once in the last one month prior to the study period [23].

\section{Ethical considerations}

The College of Health and Medical Sciences Institutional Health Research Ethics Review Committee of Haramaya University had ethically approved the study. Permission from health facilities managers and written informed consent from patients were sought before administering questionnaires. We used anonymous questionnaires to keep patients' confidentiality and the interview was conducted in a private room to assure the patients' privacy. Patients with CMD were referred for professional care in the hospitals.

\section{Results}

Socio-demographic characteristics of respondents

From the total 420 patients, all were interviewed (providing response rate $100 \%$ ); $26.0 \%$ of the respondents were males, and $71.0 \%$ were age less than 40 years. From the total participants, $53.6 \%$ were Oromo by ethnicity, $67.9 \%$ were Orthodox Christians, 37.6\% were married and living together, $39.0 \%$ get a monthly pocket money of 500-999 Ethiopian birr, $44.3 \%$ educated primary school, and $17.4 \%$ were Government employee (Table 1). 
Table 1 Socio-demographic characteristics of adult patients attending HIV follow up service in Harar town, eastern Ethiopia, 2015

\begin{tabular}{lll}
\hline Socio-demographic characteristics & Frequency $(\mathrm{N})$ & Percent (\%) \\
\hline Sex & 109 & 26.0 \\
Male & 311 & 74.0 \\
Female & & \\
Marital status & 57 & 13.6 \\
Single & 158 & 37.6 \\
Married and living together & 112 & 26.7 \\
Separated & 93 & 22.1 \\
Divorced/widowed & & \\
Ethnicity & 225 & 53.6 \\
Oromo & 118 & 28.1 \\
Amhara & 28 & 6.7 \\
Tigre & 24 & 5.7 \\
Guraghe & 15 & 3.6 \\
Harari & 10 & 2.4 \\
Others & &
\end{tabular}

Religion

Muslim

Orthodox

Protestant

Age group in years

$$
<40
$$

40-60

$>60$

Educational status

Unable to read and write

Able to read and write

Primary school

Secondary school

Diploma

Degree

Occupational status

$\begin{array}{ll}\text { House wife } & 5 \\ \text { Government employee } & 73 \\ \text { NGO employee } & 2 \\ \text { Private } & 48 \\ \text { Student } & 5 \\ \text { Daily laborer } & 1 \\ \text { Unemployed } & 562 \\ \text { Merchant } & 64 \\ \text { ncome } & \\ <200 & 70 \\ 200-499 & 39\end{array}$

200-499
Table 1 Socio-demographic characteristics of adult patients attending HIV follow up service in Harar town, eastern Ethiopia, 2015 (Continued)

\begin{tabular}{cll}
\hline Socio-demographic characteristics & Frequency $(\mathrm{N})$ & Percent (\%) \\
\hline 500-999 & 164 & 39.0 \\
$>=1000$ & 147 & 35.0 \\
\hline Others: Somali Wolayita, and sidama & &
\end{tabular}

\section{Prevalence of CMD among HIV/AIDS patients}

The result revealed that among the 420 HIV/AIDS patients those were interviewed; Using SRQ-20 questionnaire $(28.1 \%$; $95 \% \mathrm{CI} ; 26.14,30.06)$ of them had CMD.

\section{Factors associated with CMD among patients living with HIV/AIDS}

The association between CMD and independent variables were determined using bivariate and multivariate (binary logistic regression) analyses. In the final model of multivariate logistic regression analysis HIV/AIDS stage and current drinking alcohol were found having statistically significant association with CMD. However, Socio-demographic variables like: Marital status and income were statistically significant in the binary logistic regression analysis but not significant in the final model of multivariate logistic regression analysis (Table 2).

Likewise, Clinical, psychosocial and substance use factors like: perceived HIV stigma, lost job due to HIV/ AIDS, having any comorbid chronic physical health problems, and current smoking cigarettes, chewing Khat and using illicit substances were again statistically significant in the binary logistic regression analysis but not significant in the final model (Table 3).

As revealed in final multivariate logistic regression analysis, clients who have stage 4 HIV/AIDS were 3.37 times more likely to have CMD than clients with stage 1 HIV/AIDS (AOR 3.37, 95\% CI: 1.45, 7.83) and Patients who have family history of mental illness were 2.65 times more likely to develop CMD than clients who have no family history of mental illness (AOR 2.65, 95\% CI: 1.26, 5.54). Those individuals currently drinking alcohol, were more than five times more likely to develop CMD than those who are currently not drinking (AOR 5.1, 95\% CI: 2.04, 12.79) (Table 4).

\section{Discussion}

This study showed that the overall prevalence rate of common mental disorder among HIV/AIDS patients is $28.1 \%$ with the range between 26.14 and $30.06 \%$. Associated factors identified in the final model of this study were stage of HIV/AIDS, Family history of mental illness and current drinking alcohol.

In the current study the prevalence of common mental disorder among people living with HIV/AIDS is closer to the finding in south west regional hospitals 
Table 2 Binary logistic regression: Socio-demographic factors independently associated with CMD among adult patients attending HIV follow up service in Harar town, eastern Ethiopia, 2015

\begin{tabular}{|c|c|c|c|c|}
\hline Variables & $\begin{array}{l}<7 \text { (no } \\
\text { CMD) }\end{array}$ & $\begin{array}{l}>=7 \\
(\mathrm{CMD})\end{array}$ & $p$-value & $\begin{array}{l}\text { COR } \\
(95 \% \mathrm{Cl})\end{array}$ \\
\hline \multicolumn{5}{|l|}{ Sex } \\
\hline Male & 82 & 27 & Reference & Reference \\
\hline Female & 220 & 91 & 0.37 & $\begin{array}{l}1.26 \\
{[0.763-2.069]}\end{array}$ \\
\hline
\end{tabular}

Marital status

$\begin{array}{lccll}\text { Single } & 37 & 20 & 0.07 & 1.8[0.95-3.54] \\ \begin{array}{l}\text { Married \& living } \\ \text { together }\end{array} & 122 & 36 & \text { Reference } & \text { Reference } \\ \text { Separated } & 73 & 39 & 0.03 & 1.8[1.06-3.1] \\ \text { Divorced/widowed } & 70 & 23 & 0.73 & 1.1[0.6-2.03]\end{array}$

Ethnicity

Oromo
Amhara
Tigre
Guraghe
Harari
Others

Religion

Muslim

Protestant

Age group in years

$$
<40
$$

$40-60$

$>60$

Educational status write

Able to read and write

Primary school

Secondary school

Diploma

Degree

Occupational status

House wife
Government employee
NGO employee
Private
Student

Daily laborer

Unemployed

$\begin{array}{ll}171 & 54 \\ 75 & 43 \\ 22 & 6 \\ 18 & 6 \\ 9 & 6 \\ 7 & 3\end{array}$

54

Reference Reference

0.67

$0.74[0.18-2.95]$

0.68

$1.34[0.33-5.4]$

0.58

$0.64[0.13-3.24]$

0.76

$0.78[0.15-4.0]$

0.61

$1.56[0.28-8.5]$

$61-33-0.51$

1.31 [0.59-2.89]

0.62

$0.83[0.4-1.71]$

$29 \quad 12$

Reference Reference

137

$$
87
$$

21273

$\begin{array}{lll}90 & 0.14 & 1.5[0.9-2.4] \\ 26 & \text { Reference } & \text { Reference } \\ 2 & 0.9 & 1.13[0.2-5.9]\end{array}$

(25

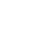

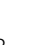

49
33

33

6

2

$\begin{array}{lll}12 & 0.68 & 1.31[0.37-4.64] \\ 19 & 0.51 & 1.5[0.45-5.0] \\ 4 & \text { Reference } & \text { Reference } \\ 10 & 0.86 & 1.12[0.31-4.07] \\ 1 & 0.96 & 1.06[0.09- \\ & & 12.28] \\ 39 & 0.10 & 2.63[0.83-8.39] \\ 17 & 0.33 & 1.85[0.54-6.33]\end{array}$

Table 2 Binary logistic regression: Socio-demographic factors independently associated with CMD among adult patients attending HIV follow up service in Harar town, eastern Ethiopia, 2015 (Continued)

\begin{tabular}{lllll}
\hline Variables & $\begin{array}{l}<7 \text { (no } \\
\text { CMD) }\end{array}$ & $\begin{array}{l}>=7 \\
(\mathrm{CMD})\end{array}$ & $p$-value & $\begin{array}{l}\text { COR } \\
(95 \% \mathrm{Cl})\end{array}$ \\
\hline $\begin{array}{c}\text { Merchant } \\
\text { Income }\end{array}$ & 48 & 16 & 0.58 & $1.42[0.42-4.83]$ \\
$<200$ & & & & \\
$200-499$ & 52 & 18 & 0.68 & $1.15[0.59-2.2]$ \\
$500-999$ & 27 & 12 & 0.33 & $1.48[0.68-3.2]$ \\
$>=1000$ & 110 & 54 & 0.05 & $1.63[1.1-2.69]$ \\
\hline
\end{tabular}

Others: Somali, Wolayita, and sidama

of Cameroon, which shows $26.7 \%$ of HIV/AIDS patients on HAART have depression [24]. On the other hand, the prevalence is greater than that found in Tanzania and South Africa $[25,26]$ in which the prevalence was 15.5 and $14.2 \%$ respectively. This variation could be due to different possible reasons like different method used to assess the condition. The study in Tanzania conducted using ICD-10 common mental health diagnosis and in South Africa they applied DSM diagnoses. But in the current study we applied SRQ-20 standardized questionnaire. The present study result is lower than the studies done in Zimbabwe and Indian setting $[27,28]$ in which the findings were 67.9 and $58.75 \%$ respectively. This difference could be the slight difference of study population nature like in the study conducted in Zimbabwe $92 \%$ of the participants were on HAART, which indicates that they could have severe illness. As the severity of HIV/AIDS increased the patients could develop CMD more [27]. But in the current study only $71.7 \%$ were on HAART and the left were pre-ART. The other possible reason could be in the present study majority of the participants were young age as $71.0 \%$ of them were at age less than 40 years. Study on common mental disorder among general population showed that older age is significantly associated with higher prevalence of common mental disorder [29].

Our study finding shown that patients who have stage 4. HIV/AIDS were more likely to develop common mental disorder (AOR 3.37, 95\% CI: 1.45, 7.83) and it is in line with the results of studies done in India and Ethiopia [27, 30]. Patients those are currently drinking alcohol are also more likely to develop common mental disorder (AOR 5.1, 95\% CI: 2.04, 12.79) and this result is supported by study conducted on common mental disorder among general population in Ethiopia [29]. As more alcohol enters the bloodstream, the areas of the brain associated with emotions and movement are affected, often resulting in exaggerated states of emotion 
Table 3 Binary logistic regression: Clinical, psychosocial and substance use factors independently associated with CMD among adult patients attending HIV follow up service in Harar town, eastern Ethiopia, 2015

\begin{tabular}{lllll}
\hline Variables & $<7$ (no & $>=7$ & p-value & COR \\
& CMD) & $(\mathrm{CMD})$ & & $(95 \% \mathrm{Cl})$
\end{tabular}

\begin{tabular}{lllll}
\hline $\begin{array}{c}\text { CD4 count } \\
<=500 \text { cell/L }\end{array}$ & 176 & 78 & 0.14 & $1.4[0.89-2.18]$ \\
$\begin{array}{c}\text { 500cell/L } \\
\text { HIV/AIDS stage }\end{array}$ & 126 & 40 & Reference & Reference \\
stage 1 & 187 & 54 & Reference & Reference \\
stage 2 & 53 & 20 & 0.4 & $1.31[0.72-2.4]$ \\
stage 3 & 46 & 27 & 0.01 & $2.03[1.2-3.6]$ \\
stage 4 & 16 & 17 & 0.001 & $3.68[1.7-7.8]$
\end{tabular}

Started taking ART

$\begin{array}{lllll}\text { Yes } & 291 & 109 & 0.09 & 0.46[0.19-1.14] \\ \text { No } & 11 & 9 & \text { Reference } & \text { Reference }\end{array}$

Perceived HIV stigma

$\begin{array}{lllll}\text { Yes } & 35 & 29 & 0.001 & 2.5[1.4-4.3] \\ \text { No } & 267 & 89 & \text { Reference } & \text { Reference }\end{array}$

Sero status of partner

$\begin{array}{lllll}\text { Positive } & 86 & 24 & 0.3 & 0.7[0.3-1.4] \\ \text { Negative } & 45 & 18 & \text { Reference } & \text { Reference } \\ \text { Do not know } & 16 & 6 & 0.9 & 0.9[0.3-2.8] \\ \text { No partner } & 155 & 70 & 0.7 & 1.13[0.6-2.1] \\ \text { Children's Sero status } & & & \\ \text { Yes } & 42 & 19 & 0.56 & 1.19[0.66-2.15] \\ \text { No } & 258 & 98 & \text { Reference } & \text { Reference } \\ \text { Do not know } & 2 & 1 & 0.82 & 1.32[0.12-14.68]\end{array}$

Partner died because of HIV/AIDS

$\begin{array}{lllll}\text { Yes } & 61 & 21 & 0.6 & 0.86[0.49-1.48] \\ \text { No } & 241 & 97 & \text { Reference } & \text { Reference }\end{array}$

Family member died because of HIV/AIDS

$\begin{array}{lllll}\text { Yes } & 61 & 22 & 0.74 & 0.91[0.53-1.57] \\ \text { No } & 240 & 95 & \text { Reference } & \text { Reference } \\ \text { Do not know } & 1 & 1 & 0.51 & 2.53[0.16-40.8] \\ \text { Hospitalized in the last month } & & & \\ \text { Yes } & 16 & 9 & 0.37 & 1.48[0.63-3.44] \\ \text { No } & 286 & 109 & \text { Reference } & \text { Reference }\end{array}$

Level of functioning decreased than usual

$\begin{array}{cccll}\text { Yes } & 48 & 28 & 0.06 & 1.6[0.97-2.78] \\ \text { No } & 251 & 89 & \text { Reference } & \text { Reference } \\ \begin{array}{ccc}\text { Do not know } \\ \text { Lost job due to HIV/AIDS }\end{array} & 1 & 0.96 & 0.94[0.09-9.16] \\ \begin{array}{c}\text { Yes } \\ \text { Y3 }\end{array} & 26 & 0.05 & 1.7[1.1-2.93]\end{array}$

Table 3 Binary logistic regression: Clinical, psychosocial and substance use factors independently associated with CMD among adult patients attending HIV follow up service in Harar town, eastern Ethiopia, 2015 (Continued)

\begin{tabular}{|c|c|c|c|c|}
\hline Variables & $\begin{array}{l}<7 \text { (no } \\
\text { CMD) }\end{array}$ & $\begin{array}{l}>=7 \\
(\mathrm{CMD})\end{array}$ & $p$-value & $\begin{array}{l}\text { COR } \\
(95 \% \mathrm{Cl})\end{array}$ \\
\hline No & 259 & 92 & Reference & Reference \\
\hline \multicolumn{5}{|c|}{$\begin{array}{l}\text { Family history of } \\
\text { mental illness }\end{array}$} \\
\hline Yes & 18 & 23 & 0.001 & $3.8[1.98-7.38]$ \\
\hline No & 284 & 95 & Reference & Reference \\
\hline \multicolumn{5}{|c|}{$\begin{array}{l}\text { Having any comorbid } \\
\text { chronic physical health problem }\end{array}$} \\
\hline Yes & 11 & 12 & 0.01 & $2.99[1.28-6.99$ \\
\hline No & 291 & 106 & Reference & Reference \\
\hline \multicolumn{5}{|c|}{$\begin{array}{l}\text { Smoked cigarettes at least once } \\
\text { during the last three months }\end{array}$} \\
\hline Yes & 13 & 13 & 0.01 & $2.8[1.24-6.13]$ \\
\hline No & 289 & 105 & Reference & Reference \\
\hline \multicolumn{5}{|c|}{$\begin{array}{l}\text { Alcohol used at least once during } \\
\text { the last three months }\end{array}$} \\
\hline Yes & 30 & 39 & 0.001 & $4.48[2.61-7.66$ \\
\hline No & 272 & 79 & Reference & Reference \\
\hline
\end{tabular}

Chewed Khat at least once during the last three months

$\begin{array}{lllll}\text { Yes } & 48 & 37 & 0.001 & 2.417[1.471-3.971] \\ \text { No } & 254 & 81 & \text { Reference } & \text { Reference }\end{array}$

Used illicit substances at least once during the last three months

\begin{tabular}{lllll} 
Yes & 17 & 16 & 0.008 & $2.63[1.28-5.39]$ \\
No & 285 & 102 & Reference & Reference \\
\hline
\end{tabular}

(anger, withdrawal, depression or aggressiveness) and uncoordinated muscle movements [31]. Also, our study revealed that patients who had family history of mental illness were more likely to have common mental disorder as compared to patients who have no family history of mental illness (AOR 2.65, 95\% CI: 1.26, 5.54).

\section{Limitations of the study}

The study was hospital based and some patients with severe common mental disorder might unlikely to be available in the hospital due to their severity of common mental disorder during data collection period. This could influence the prevalence of common mental disorder and it might not be generalized to the total population of people living with HIV/AIDS in the region. Also, our study was cross-sectional and it cannot show the cause-effect relationship between common mental disorder and independent variables.

\section{Conclusions}

In this study the prevalence of CMD is relatively high. HIV/AIDS stage, having family history of mental illness 
Table 4 Multivariate logistic regression: Socio-demographic, Clinical, psychosocial and substance use factors independently associated with CMD among adult patients attending HIV follow up service in Harar town, eastern Ethiopia, 2015

\begin{tabular}{|c|c|c|c|c|}
\hline Variables & $\begin{array}{l}<7 \text { (no } \\
\text { CMD) }\end{array}$ & $\begin{array}{l}>=7 \\
(\mathrm{CMD})\end{array}$ & $p$-value & $\begin{array}{l}\text { AOR } \\
(95 \% \mathrm{Cl})\end{array}$ \\
\hline \multicolumn{5}{|l|}{ Marital status } \\
\hline Single & 37 & 20 & 0.07 & $\begin{array}{l}2.01 \\
{[0.94-4.30]}\end{array}$ \\
\hline $\begin{array}{l}\text { Married and living } \\
\text { together }\end{array}$ & 122 & 36 & Reference & Reference \\
\hline Separated & 73 & 39 & 0.3 & $\begin{array}{l}1.4[0.75- \\
2.58]\end{array}$ \\
\hline Divorced/widowed & 70 & 23 & 0.98 & $\begin{array}{l}0.9[0.49- \\
1.98]\end{array}$ \\
\hline \multicolumn{5}{|l|}{ Income } \\
\hline$<200$ & 52 & 18 & 0.75 & $\begin{array}{l}0.88 \\
{[0.41-1.88]}\end{array}$ \\
\hline $200-499$ & 27 & 12 & 0.98 & $\begin{array}{l}1.01 \\
{[0.41-2.45]}\end{array}$ \\
\hline 500-999 & 110 & 54 & 1.18 & $\begin{array}{l}1.5 \\
{[0.84-2.59]}\end{array}$ \\
\hline$>=1000$ & 113 & 34 & Reference & Reference \\
\hline \multicolumn{5}{|l|}{ HIV/AIDS stage } \\
\hline stage 1 & 187 & 54 & Reference & Reference \\
\hline stage 2 & 53 & 20 & 0.86 & $\begin{array}{l}0.94 \\
{[0.48-1.84]}\end{array}$ \\
\hline stage 3 & 46 & 27 & 0.28 & $\begin{array}{l}1.42 \\
{[0.75-2.69]}\end{array}$ \\
\hline stage 4 & 16 & 17 & 0.005 & $\begin{array}{l}3.37 \\
{[1.45-7.83]}\end{array}$ \\
\hline
\end{tabular}

Perceived HIV stigma

$\begin{array}{lllll}\text { Yes } & 35 & 29 & 0.09 & 1.78 \\ & & & & {[0.92-3.43]} \\ \text { No } & 267 & 89 & \text { Reference } & \text { Reference }\end{array}$

Lost job due to HIV/AIDS

Yes

No

Family history of mental illness

$$
\text { Yes }
$$

No

Having any chronic physical health problem

Yes

Smoked cigarettes at least once during the last three months

$\begin{array}{lcccl}\text { Yes } & 13 & 13 & 0.94 & 1.05 \\ & & & & {[0.34-3.19]} \\ \text { No } & 289 & 105 & \text { Reference } & \text { Reference }\end{array}$

Table 4 Multivariate logistic regression: Socio-demographic, Clinical, psychosocial and substance use factors independently associated with CMD among adult patients attending HIV follow up service in Harar town, eastern Ethiopia, 2015 (Continued)

\begin{tabular}{lllll}
\hline Variables & $\begin{array}{c}<7 \text { (no } \\
\text { CMD) }\end{array}$ & $\begin{array}{l}>=7 \\
(\mathrm{CMD})\end{array}$ & $p$-value & $\begin{array}{l}\text { AOR } \\
(95 \% \mathrm{Cl})\end{array}$ \\
\hline $\begin{array}{l}\text { Alcohol used at least once } \\
\text { during the last three months }\end{array}$ & & & & \\
$\quad$ Yes & 30 & 39 & 0.001 & $\begin{array}{l}5.1 \\
\text { [2.04-12.79] }\end{array}$ \\
No & 272 & 79 & Reference & Reference
\end{tabular}

Chewed Khat at least once during the last three months

$\begin{array}{lllll}\text { Yes } & 48 & 37 & 0.21 & 0.56 \\ & & & & {[0.23-1.38]} \\ \text { No } & 254 & 81 & \text { Reference } & \text { Reference }\end{array}$

Used illicit substances at least once during the last three months

\begin{tabular}{lllll} 
Yes & 17 & 16 & 0.086 & 2.27 \\
& & & & $\begin{array}{l}0.99-5.98] \\
\text { No }\end{array}$ \\
\hline
\end{tabular}

and current drinking alcohol were the identified factors those have significant association with common mental disorder among patients living with HIV/AIDS. The study finding will provides information to form rational foundation for prevention and planning to bring change in contributing factors for developing CMD among patients living with HIV/AIDS and also will be base line information for further study. The study recommended that it is important to control the progression of HIV like early detecting and treating opportunistic infections.

\section{Abbreviations}

AIDS: Acquired Immune Deficiency Syndrome; AOR: Adjusted Odds Ratio; ART: Antiretroviral Therapy; CMD: Common Mental Disorders; COR: Crude Odds Ratio; FGAE: Family Guidance Association of Ethiopia; HAART: Highly Active Antiretroviral Therapy; HIV: Human Immune Virus; IRERC: Institutional Research Ethics Review Committee; LAMIC: Low- and Middle-Income Countries; MDD: Major Depressive Disorder; PLWHA: People Living with HIV/AIDS; QOL: Quality of Life; SRQ: Self-Reported Questionnaire; STI: Sexually Transmitted Infections; WHO: World Health Organization

\section{Acknowledgments}

Not applicable.

\section{Funding}

Haramaya University College of Health and Medical Sciences funded from data collection to analysis.

Availability of data and materials

The datasets analyzed during the current study is available from the corresponding author on reasonable request.

\section{Authors' contributions}

AM contributed to the designing research, conduct and analysis and in the review of the manuscript. LN contributed to the design, conduct, and analysis of the research and the review of the manuscript. $\mathrm{GH}$ contributed to the design, conduct, and analysis of the research and the review of the manuscript. TA contributed to the design, conduct, and analysis of the research, drafting the manuscript, critically reviewed and approved the 
manuscript for publication. All authors read and approved the final manuscript.

\section{Ethics approval and consent to participate}

The study was conducted after approval obtained from the College of Health and Medical Sciences, Institutional Research Ethics Review Committee (IRERC) of Haramaya University. Written informed consent was obtained from the study participants after providing a clear explanation of the objective of the study. The collected data were kept confidential. Participants' right to refuse and the chance to ask anything about the study was respected. The names of the participants were not written.

\section{Consent for publication}

Not applicable.

\section{Competing interests}

The authors declare that they have no competing interests.

\section{Publisher's Note}

Springer Nature remains neutral with regard to jurisdictional claims in published maps and institutional affiliations.

\section{Author details}

${ }^{1}$ Department of Nursing, College of health and medical sciences, School of Nursing and Midwifery, Haramaya University, Harar, Ethiopia. ${ }^{2}$ Department of Psychiatry, College of health and medical sciences, School of Nursing and Midwifery, Haramaya University, Harar, Ethiopia. ${ }^{3}$ Centre for International Health, Ludwig Maxmillians University, Munich, Germany.

Received: 28 August 2018 Accepted: 8 February 2019

Published online: 22 February 2019

\section{References}

1. Baingana F, Thomas R, Comblain C. HIV/AIDS and. mental health. 2005.

2. Mahajan AP, et al. Stigma in the HIV/AIDS epidemic: a review of the literature and recommendations for the way forward. AIDS (London, England). 2008;22(Suppl 2):S67.

3. Altevogt, B., et al. Mental, neurological and substance use disorders in Sub-Saharan Africa: reducing the treatment gap, improving quality of care. Workshop summary. in Mental, neurological and substance use disorders in Sub-Saharan Africa: reducing the treatment gap, improving quality of care. Workshop summary. 2010. National Academies Press.

4. Bing $E G$, et al. Psychiatric disorders and drug use among human immunodeficiency virus-infected adults in the United States. Arch Gen Psychiatry. 2001;58(8):721-8.

5. Lazarus, R. and M. Freeman, Primary-Level Mental Health Care for Common Mental Disorder in Resource-Poor Settings: Models \& Practice. A literature review. Pretoria: Medical Research Council, 2009.

6. Kroenke K, Jackson JL, PA MJC. Depressive and anxiety disorders in patients presenting with physical complaints: clinical predictors and outcome. Am J Med. 1997;103(5):339-47.

7. Adewuya $\mathrm{AO}$, et al. Psychiatric disorders among the HIV-positive population in Nigeria: a control study. J Psychosom Res. 2007;63(2):203-6.

8. Deribew A, et al. Common mental disorders in TB/HIV co-infected patients in Ethiopia. BMC Infect Dis. 2010;10(1):201

9. Pence BW. The impact of mental health and traumatic life experiences on antiretroviral treatment outcomes for people living with HIV/AIDS. J Antimicrob Chemother. 2009:63(4):636-40.

10. Petrushkin H, Boardman J, Ovuga E. Psychiatric disorders in HIV-positive individuals in urban Uganda. Psychiatr Bull. 2005:29(12):455-8.

11. Vitiello $B$, et al. Use of psychotropic medications among HIV-infected patients in the United States. Am J Psychiatr. 2003;160(3):547-54.

12. Whetten $\mathrm{K}$, et al. A brief mental health and substance abuse screener for persons with HIV. AIDS Patient Care \& STDs. 2005;19(2):89-99.

13. Kessler RC, et al. The epidemiology of major depressive disorder: results from the National Comorbidity Survey Replication (NCS-R). Jama. 2003; 289(23):3095-105.

14. Tesfaye $M$, et al. Detecting postnatal common mental disorders in Addis Ababa, Ethiopia: validation of the Edinburgh postnatal depression scale and Kessler scales. J Affect Disord. 2010;122(1-2):102-8.
15. Maj M, et al. WHO neuropsychiatric AIDS study, cross-sectional phase I: study design and psychiatric findings. Arch Gen Psychiatry. 1994:51(1):39-49.

16. Chandra PS, Desai G, Ranjan S. HIV \& psychiatric disorders. Indian J Med Res. 2005;121(4):451-67.

17. Ciesla JA, Roberts JE. Meta-analysis of the relationship between HIV infection and risk for depressive disorders. Am J Psychiatr. 2001;158(5):725-30.

18. Stall RD, et al. An outcome evaluation to measure changes in sexual risktaking among gay men undergoing substance use disorder treatment. J Stud Alcohol. 1999;60(6):837-45.

19. Olagunju AT, et al. A study on epidemiological profile of anxiety disorders among people living with HIV/AIDS in a sub-Saharan Africa HIV clinic. AIDS Behav. 2012;16(8):2192-7.

20. Bernard C, Dabis F, de Rekeneire N. Prevalence and factors associated with depression in people living with HIV in sub-Saharan Africa: a systematic review and meta-analysis. PLoS One. 2017;12(8):e0181960.

21. Barreto do Carmo MB, et al. Screening for common mental disorders using the SRQ-20 in Brazil: what are the alternative strategies for analysis? Rev Bras Psiquiatr. 2018;40(2):115-22.

22. Hanlon C, et al. Detecting perinatal common mental disorders in Ethiopia: validation of the self-reporting questionnaire and Edinburgh postnatal depression scale. J Affect Disord. 2008;108(3):251-62.

23. Lakew $\mathrm{A}$, et al. Prevalence of catha edulis (khat) chewing and its associated factors among ataye secondary school students in northern shoa, Ethiopia. Advances in Applied Sociology. 2014:4(10):225.

24. Ngum PA, et al. Depression among HIV/AIDS patients on highly active antiretroviral therapy in the southwest regional hospitals of Cameroon: a cross-sectional study. Neurology and therapy. 2017;6(1):103-14.

25. Kagee $A$, et al. The prevalence of common mental disorders among south Africans seeking HIV testing. AIDS Behav. 2017;21(6):1511-7.

26. Marwick KF, Kaaya SF. Prevalence of depression and anxiety disorders in HIV-positive outpatients in rural Tanzania. AIDS Care. 2010:22(4):415-9.

27. Bhatia M, Munjal S. Prevalence of depression in people living with HIV/AIDS undergoing ART and factors associated with it. J Clin Diagn Res. 2014;8(10): WC01.

28. Chibanda D, et al. Prevalence and correlates of probable common mental disorders in a population with high prevalence of HIV in Zimbabwe. BMC psychiatry. 2016:16(1):55

29. Kerebih $\mathrm{H}$, Soboka M. Prevalence of common mental disorders and associated factors among residents of Jimma town, South West Ethiopia. Population. 2016;8:6-8.

30. Tesfaw $\mathrm{G}$, et al. Prevalence and correlates of depression and anxiety among patients with HIV on-follow up at alert hospital, Addis Ababa, Ethiopia. BMC psychiatry. 2016;16(1):368.

31. Cornah, D., Cheers? Understanding the relationship between alcohol and mental health. Mental Health Foundation, 2006.

Ready to submit your research? Choose BMC and benefit from:

- fast, convenient online submission

- thorough peer review by experienced researchers in your field

- rapid publication on acceptance

- support for research data, including large and complex data types

- gold Open Access which fosters wider collaboration and increased citations

- maximum visibility for your research: over $100 \mathrm{M}$ website views per year

At BMC, research is always in progress.

Learn more biomedcentral.com/submission 